AWEJ for Translation \& Literary Studies Volume, 1 Number 3, August 2017

Pp.177-195

DOI: http://dx.doi.org/10.24093/awejtls/vol1no3.12

\title{
The Role of Culture in Dubbing TV Advertisements into Arabic: The Case of Chocolate Commercials
}

\author{
Ameena Haroun Abdulla Al-Haroon \\ Audiovisual Translation Graduate Student, College of Humanities and Social Sciences \\ Hamad Bin Khalifa University, Doha, Qatar
}

\author{
Rashid Yahiaoui \\ Assistant Professor, College of Humanities and Social Sciences \\ Hamad Bin Khalifa University, Doha, Qatar
}

\begin{abstract}
This study aims to explore the transcreation of television advertisements that were dubbed from English into vernacular and modern standard Arabic, and to propose translation as an integral part of marketing a product internationally. The study attempts to achieve these aims by looking at the pragmatic concept of presupposition in translation studies, guided by micro-translation strategies of cultural themes. The study employs Maslow's Hierarchy of Needs (1943) and Hofstede's Cultural Dimensions (1984) to analyze the translation of three cultural themes: methods of persuasion, stereotypes, and humor. Further themes, per each cultural themes are explored: persuasion through foreignization, persuasion through localization of norms and preferences, persuasion through adapting types of register, portraying the Arab culture as storytellers, verbalizing stereotypes through linguistic clichés and idioms, hyperbole in humor, and modification of irony in humor. The study concludes that micro-translation strategies: (1) in terms of cultural themes, are not exclusive to either a Modern Standard Arabic (MSA) or a vernacular Arabic dialect; and (2) are used concurrently across cultural sub-themes.

Keywords: Advertisement translation, cultural translation, dubbing, localization, transcreation, Arabic dialects, Modern Standard Arabic

Cite as: Al-Haroon, A. H. A. , \& Yahiaoui, R. (2017). The Role of Culture in Dubbing TV Advertisements into Arabic: The Case of Chocolate Commercials. Arab World English Journal for Translation \& Literary Studies, 1(3).

DOI: http://dx.doi.org/10.24093/awejtls/vol1no3.12
\end{abstract}

Arab World English Journal for Translation \& Literary Studies

eISSN: 2550-1542 |www.awej-tls.org 